\title{
ДИАГНОСТИКА И ЛЕЧЕНИЕ ДЕПРЕССИИ ПРИ НЕВРОЛОГИЧЕСКИХ ЗАБОЛЕВАНИЯХ
}

\author{
Д.м.н. Ф. Н.Исмаилов
}

Центр Психического Здоровья МЗ АР

Д епрессия является самым распространенным психическим расстройством у неврологическихбольных. Согласно международной статистике распространенность депрессии в течение 2-х лет после перенесенного инсульта составляет от 30-72\%, при болезни Паркинсона 40-50\%, при рассеянном склерозе $20-54 \%$, при эпилепсии 45-55\%, при хорее Гантингтона 41$66 \%$, при черепно-мозговой травме 50-53\% [1].

Коморбидность депрессии при неврологических заболеваниях может формироваться тремя способами. Во-первых депрессия может предшествовать развитию неврологической патологии (при некоторых видах деменции) [2], во-вторых депрессия может возникать одновременно с неврологическим заболеванием (при болезни Паркинсона) [3], наконец депрессия может возникать после манифестации неврологического расстройства (после инсульта) [4].

Депрессия у больных неврологическими расстройствами ассоциируется с худшим прогнозом, ухудшением качества жизни [5], недостаточной приверженностью соблюдения режима лечения [6], нарушениями взаимоотношения больных и персонала [7] и повышением показателей смертности [8].

На сегодняшний день наиболее весомым фактором риска возникновения депрессии у неврологических больных являются ухудшение физического и когнитивного функционирования, которые ассоциируются с выраженным дистрессом в повседневной жизнедеятельности [9]. Важно отметить, что дисстресс, связанный с ограничением функциональной адаптации влияет не только на самого пациента, но и на членов его семьи, которые испытывают чувство неопределенности в отношении будущего и чувство утраты благополучного прошлого [10].

Кроме того, большое значение для развития депрессии могут иметь непосредственно нейробиологические факторы, сопряженные с неврологической патологией. В частности *e-mail: fuadismayilov@psychiatry.az структурные изменения при многих неврологических заболеваниях могут охватывать нейронные сети, отвечающие за регулирование эмоций $[11,12,13]$. Вместе с тем, как показывают исследования, роль нейроанатомических изменений может объяснять менее $50 \%$ дисперсиидепрессивных симптомов [14].

Сложности выявления и диагностики депрессии у неврологических больных. На сегодняшний день согласно мировой статистике больные депрессией сопровождающей неврологические заболевания недостаточно хорошо выявляются и не получают адекватного лечения [15].

Недостаточное выявление таких больных в первую очередь связанос совпадением многих симптомов депрессии с симптомами неврологических расстройств. Как видно из таблицы 1, большинство критериев для диагностики депрессивного расстройства перекликается с клинической картиной многих неврологических болезней.

Таблица 1

Критерии МКБ-10 для диагностики депрессии F32 Депрессивный эпизод

\section{А. Основные симптомы:}

1. снижение настроения, представленное почти ежедневно и захватывающее большую часть дня, которое имеет продолжительность не менее двух недель;

2. отчетливое снижение интереса или удовольствия от деятельности, которая обычно приятна для больного; 3. снижение энергии и повышения утомляемости.

\section{В. Дополнительные симптомы:}

1. снижение уверенности и самооценки;

2. беспричинное чувство самоосуждения или чрезмерное и неадекватное чувство вины;

3. повторяющиеся мысли о смерти или суициде или суицидальное поведение;

4. проявления и жалобы на уменьшение способности обдумывать или концентрироваться;

5. нарушение психомоторной активности с ажитацией или заторможенностью (субъективно или объективно); 6. нарушение сна любого типа;

7. изменение аппетита (повышение или понижение) с соответствующим изменением веса тела. 
Так, симптомы болезни Паркинсона включают моторную заторможенность, брадифрению, нарушения сна и аппетита, снижение концентрации внимания и ослабление либидо, которыевстречаются придепрессии. Для больных перенесших инсульт характерны трудности коммуникации, нарушение фасциальной и эмоциональной экспрессии, вегетативные симптомы, которые могут маскировать проявления де- прессии. Кроме того, депрессия у неврологических больных может интерпретироваться как побочное действие лекарственной терапии.

Очень часто, депрессивные состояния у таких больных могут создавать впечатление деменции, обусловленной неврологическим заболеванием. В таблице 2 представлены критерии дифференциальной диагностики когнитивных нарушений при деменции и депрессии.

Таблица 2

Дифференциация когнитивных нарушений

\begin{tabular}{|c|c|c|}
\hline Характеристики & Депрессия & Деменция \\
\hline Анамнез и течение & $\begin{array}{l}\text { Четко обозначенное начало } \\
\text { Относительно короткий период бо- } \\
\text { лезни } \\
\text { Стремительная динамика } \\
\text { В анамнезе депрессивные эпизоды }\end{array}$ & $\begin{array}{l}\text { Отсутствие четкого начала } \\
\text { Длительный период болезни } \\
\text { Начальные признаки слабо выражены } \\
\text { Отсутствие анамнестических данных } \\
\text { о депрессии }\end{array}$ \\
\hline Клиническая картина & $\begin{array}{l}\text { Жалобы на когнитивную дисфунк- } \\
\text { цию } \\
\text { Незначительные усилия при выпол- } \\
\text { нении когнитивных задач } \\
\text { Аффективная насыщенность } \\
\text { Поведение не соответствует утрате } \\
\text { интеллектуальных функций } \\
\text { Дисфункция редко проявляется по } \\
\text { ночам }\end{array}$ & $\begin{array}{l}\text { Отсутствие жалоб на снижение па- } \\
\text { мяти и интеллекта } \\
\text { Значительные усилия при решении } \\
\text { когнитивных задач } \\
\text { Поверхностная эмоциональность } \\
\text { Поведение конгруэнтно утрате ко- } \\
\text { гнитивных функций } \\
\text { Нарушение когнитивных функций } \\
\text { особенно заметна ночью }\end{array}$ \\
\hline Данные обследования & $\begin{array}{l}\text { Часто повторяющиеся ответы "Я не } \\
\text { знаю" без попыток выполнения } \\
\text { Ухудшение памяти на прошлые со- } \\
\text { бытия } \\
\text { Определенные провалы в памяти } \\
\text { Исполнительные функции распреде- } \\
\text { лены неравномерно }\end{array}$ & $\begin{array}{l}\text { Имеется стремление справиться с за- } \\
\text { данием } \\
\text { Ухудшение памяти на недавние со- } \\
\text { бытия } \\
\text { Отсутствие провалов в памяти } \\
\text { Равномерное нарушение исполни- } \\
\text { тельных функций }\end{array}$ \\
\hline
\end{tabular}

Не случайно в клинических рекомендациях по лечению депрессии у больных с коморбидной патологией особо подчеркивается, что комплексное обследование таких больных должно основываться не только на оценке симптомов, но и на степени функциональной дезадаптации и длительности эпизода [16]. Неслучайно многие шкалы, предназначенные для количественной оценки выраженности депрессивных симптомов обнаруживают низкуювалидность при диагностике депрессии в неврологической практике.

\section{Лечение депрессии у неврологических больных}

Хотя в литературе имеются данные о применении антидепрессантов при лечении отдельных неврологических заболеваний, эффективность лечения депрессии при неврологических болезнях как целостной категории до недавне- го времени остается малоизученной. В то же время систематический обзор применения антидепрессантов позволяет определить возможные различия в действии антидепрессантов у неврологических больных по сравнению с другими пациентами с коморбидной патологией исоматически здоровыми лицами [17]. До 2006 г. Американская Ассоциация Неврологов с сомнением относилась к возможности применения антидепрессантов в связи с возможными побочными эффектами со стороны ЦНС [18].

В 2011 году британские исследователи опубликовали систематических обзор 18 рандомизированных клинических испытаний посвященных применению антидепрессантов в неврологической практике [19]. Среди этих исследований 4 относились к изучению эффективности 
трициклических антидепрессантов (амитриптилин, нортриптилин, дезипрамин), 10 - к исследованию действия СИОЗС (сертралин, флуоксатн, эсциталопрам, пароксетин), а еще 4 - к антидепрессантам относящимся к другим группам (рибоксетин,тразодон, митразапин, атомоксетин). В ходе мета-анализа удалось установить статистически значимую большую эффективность антидепрессантов по сравнению с плацебо в течение 4-18 недель после рандомизации. При этом количество пациентов выбывших из исследований не различалось между группами пациентов лечившихся антидепрессантами и плацебо. Сравнительный анализ трициклических антидепрессантов и СИОЗС не выявил преимуществ в эффективности у этих препаратов.

В то же время при назначении препаратов для лечения депрессии у неврологических больных необходимо учитывать фактор переносимости антидепрессантов, поэтому большой интерес вызывают новейшие типы антидепрессантов имеющих наиболее высокий профиль безопасности. В этой связи в 2012 г. в Российской Федерации было начато многоцентровое натуралистическое исследование "Резонанс", целью которого является изучение терапевтической эффективности мелатонинергического антидепрессанта агамелатина. На сегодняшний день получены первые результаты, свидетельствующие о высокой терапевтической активности этого препарата при депрессии у больных с различными неврологическими заболеваниями [20].

Влияние лечения на качество жизни, адаптацию, когнитивные функции. Данные о влиянии

\section{СПИСОК ЛИТЕРАТУРЫ}

1. Raskind MA. Diagnosis and treatment of depression comorbid with neurologic disorders. Am J Med 2008;121(11 Suppl 2):S28e37.

2. Patten SB, Beck CA, Williams JV, et al. Major depression in multiple sclerosis: a population-based perspective Neurology 2003;61:1524-7.

3. Ghazi-Noori S, Chung TH, Deane KHO, et al. Therapies for depression in Parkinson's disease (Cochrane Review). In: The Cochrane Library, Issue 3, 2004. Chichester, UK: John Wiley \& Sons Ltd.

4. Anderson CS, Hackett ML, House AO. Interventions for preventing depression after stroke. The Cochrane Library. Issue 3, Chichester, UK: John Wiley and Sons, Ltd, 2004

5. Hays RD, Wells KB, Sherbourne CD, et al. Functioning and well-being outcomes of patients with depression com- терапии депрессии при неврологических заболеваниях на качество жизни и функциональную адаптацию пациентов носят противоречивый характер [19]. Различия результатов исследований могут объясняться применением различных подходов к оценке качества жизни, а так же фактом того, что улучшение качества жизни и адаптации требуют значительно большего периода наблюдения, чем редукция депрессивных симптомов.

Вместе с тем данные как минимум трех РКИ свидетельствуют о значительном улучшении когнитивных функций у больных различными неврологическими заболеваниями после лечения депрессии. В этом случае трудно судить идет ли речь об улучшении когнитивных функций связанных с псевдодеменцией при депрессии или лечение депрессии способствует реальному восстановлению интелектуально-мнестических способностей, сниженных вследствие поражения ЦНС.

Важным аспектом лечения и профилактики депрессии у больных неврологическими заболеваниями является психотерапия и психосоциальная реабилитация. К настоящему времени накоплено множество доказательств эффективности психотерапевтических вмешательств при различных формах неврологической патологии. Наиболее изученными с точки зрения доказательной медицины являются интерперсональная психотерапия и когнитивноповеденческая терапия. Внедрение этих методов в практику лечения и реабилитации неврологических больных требует развития интегративного мультидисциплинарного подхода.

pared with chronic general medical illnesses. Arch Gen Psychiatry 1995;52:11-19.

6. DiMatteo MR, Lepper HS, Croghan TW. Depression is a risk factor for noncompliance with medical treatment: meta-analysis of the effects of anxiety and depression on patient adherence. Arch Intern Med 2000;160:2101-7

7. Boulanger L, Zhao Y, Bao Y, et al. A retrospective study on the impact of comorbid depression or anxiety on healthcare resource use and costs among diabetic neuropathy patients. BMC Health Serv Res 2009;9:111.

8. House A, Knapp P, Bamford J, et al. Mortality at 12 and 24 months after stroke may be associated with depressive symptoms at 1 month. Stroke 2001;32:696-701.

9. Lewinsohn, P. M., Mermelstein, R. M., Alexander, C., MacPhillamy, D. J. (1985). The unpleasant events schedule: A scale for the measurement of aversive events. 
Journal of Clinical Psychology, 41(4), 483-498.

10. Voss, W. D., Arnett, P. A., Higginson, C. I., Randolph, J. J., Campos, M. D., \&Dyck, D. G. (2002). Contributing factors to depressed mood in multiple sclerosis. Archives of Clinical Neuropsychology, 17(2), 103-115.

11. Feinstein, A., Roy, P., Lobaugh, N., Feinstein, K., O'Connor, P., \& Black, S. (2004). Structural brain abnormalities in multiple sclerosis patients with major depression. Neurology, 62 (4), 586-590.

12. Remy, P., Doder, M., Lees, A., Turjanski, N., Brooks, D. (2005). Depression in Parkinson's disease: Loss of dopamine and noradrenaline innervation in the limbic system. Brain, 128(6),1314-1322.

13. Singh, A., et al. (2000). Functional and neuroanatomical correlations in post-stroke depression: The Sunnybrook Stroke Study. Stroke, 31 (3), 637-644

14. Arnett, P. A., \&Strober, L. B. (2011). Cognitive and neurobehavioral features in multiple sclerosis. Expert Review of Neurotherapeutics, 11 (3), 411-424.

15. Rickards H. Depression in neurological disorders: Parkinson's disease, multiple sclerosis, and stroke. J NeurolNeurosurg Psychiatry. 2005 Mar;76Suppl 1:i48-52.
16. National Institute for Health and Clinical Excellence. Depression in adults with a chronic physical health problem. Clinical guideline 91, NICE, London, UK

17. Rayner L, Price A, Evans A, et al. Antidepressants for depression in physically ill people. Cochrane Database Syst Rev 2010;3

18. Miyasaki JM, Shannon K, Voon V, et al. Practice parameter: evaluation and treatment of depression, psychosis, and dementia in Parkinson disease (an evidencebased review): report of the Quality Standards Subcommittee of the American Academy of Neurology. Neurology 2006;66:996-1002.

19. Price A, Rayner L, Okon-Rocha E, Evans A, Valsraj K, Higginson IJ, Hotopf M. Antidepressants for the treatment of depression in neurological disorders: a systematic review and meta-analysis of randomised controlled trials. $\mathbf{J}$ NeurolNeurosurg Psychiatry. 2011 Aug;82(8):914-23.

20. Воробьева О.В. Вальдоксан в терапии депрессии в неврологической практике: результаты российского многоцентрового натуралистического исследования "Резонанс"Журнал Неврологии и Психиатрии им. С.С.Корсакова 2012;9:47-51

\title{
SUMMARY
}

\section{DIAGNOSTICS AND TREATMENT OF DEPRESSION IN NEUROLOGICAL DISORDERS}

\author{
F. N. Ismayilov MD, DSc \\ Mental Health Centre of the Ministry of Health
}

Despite the high prevalence of depression in people with neurological disorders, it is not properly recognized and addressed in clinical practice. This review aims to emphasize the importance of depression in people suffering from various neurological disorders. The use of different antidepressants is uncertain as well as their accessibility and tolerability for neurological patients. Also it is important to determine an impact of antidepressant treatment on quality of life, psychosocial functioning and cognition. The review advocates for integrative multidisciplinary approach towards care provision for patients with neurological disorders.

\section{XÜLASə}

\section{NEVROLOJI XəSTOLIKLOR ZAMANI DEPRESSIYYANIN DİAQNOSTIKKASI Və MÜALICCOSI}

\author{
t.e.d. F.N.İsmayılov \\ AR SN Psixi Să̆lamlıq Markazi
}

\begin{abstract}
Nevroloji xəstələrdə depressiyanın çox yayılmasına baxmayaraq, kliniki təcrübədə bu hal tanınmır və dəqiq əksini tapmamışdır. Bu icmalda müxtəlif nevroloji xəstəliklər zamanı depressiyanın vacibliyi vurğulanır. Hal-hazırda nevroloji xəstələr üçün istifadə olunun antidepressantların əhəmiyyəti və təhlükəsizliyi haqqında tam məlumat mövcud deyil. Eyni zamanda antidepressantların xəstələrin həyat keyfiyyəti, psixososial adaptasiya və koqnitiv funksiyalarına təsirini müəyyənləşdirmək zəruridir. İcmal nevroloji xəstələrə inteqrativ çoxsahəli yardımın göstərilməsini nəzərdə tutur.
\end{abstract}

